\title{
Health literacy, health perception and related factors among different ethnic groups: a cross-sectional study in southeastern Turkey
}

\author{
Gülhan Yiğitalp ${ }^{1 *}$ (D) Vasfiye Bayram Değer ${ }^{2}$ (D) and Sema Çifçi ${ }^{2}$
}

\begin{abstract}
Background: Low levels of health literacy are associated with increased hospitalization rates, problems regarding the proper intake of medications, poor general health and increased mortality rates. It is a well-known fact that health literacy differs among ethnic groups and ethnic minorities, in particular, are known to have a low level of health literacy. The present study aimed to reveal the levels of health literacy among different ethnic groups and the affecting factors as well as the relationship between health literacy and health perceptions.

Methods: This cross-sectional study was carried out with different ethnic groups (Kurdish, Arab, Turkish and Assyrian origin), between 18 and 65 years old in the province of Mardin in Turkey. The study was conducted with a total of 600 people. The European Health Literacy Scale-Turkish Adaptation (EHLS-TR) and Health Perception Scale (HPS) were used for measurement. Descriptive analysis, Mann Whitney U Test, Kruskal Wallis Test and Spearman correlation were used in the data analysis.

Results: It was found that $80.7 \%$ of the participants had relatively low levels of health literacy. The lowest levels of health literacy were among those of Kurdish origin. There were correlations between sufficient levels of health literacy and several factors including being of Assyrian origin, being 50-65 years old, living in a nuclear family, being a secondary school graduate, having a high financial status, being retired, evaluating one's own health status as good, obtaining health information from healthcare professionals, preferring to visit a state hospital to seek medical assistance first, smoking and drinking alcohol. A positive correlation was also identified between the levels of health literacy and health perception.
\end{abstract}

Conclusions: It is essential to develop programs to increase health literacy for the public and, in particular, for the ethnic groups that are disadvantaged in many aspects in the context of health literacy.

Keywords: Ethnic group, Health literacy, Health perception, Turkey

\footnotetext{
*Correspondence: g.yigitalpp@gmail.com

'Department of Nursing, Diyarbakir Atatürk School of Health, Dicle University, Diyarbakır, Turkey

Full list of author information is available at the end of the article
}

(c) The Author(s). 2021 Open Access This article is licensed under a Creative Commons Attribution 4.0 International License, which permits use, sharing, adaptation, distribution and reproduction in any medium or format, as long as you give appropriate credit to the original author(s) and the source, provide a link to the Creative Commons licence, and indicate if changes were made. The images or other third party material in this article are included in the article's Creative Commons licence, unless indicated otherwise in a credit line to the material. If material is not included in the article's Creative Commons licence and your intended use is not permitted by statutory regulation or exceeds the permitted use, you will need to obtain permission directly from the copyright holder. To view a copy of this licence, visit http://creativecommons.org/licenses/by/4.0/. The Creative Commons Public Domain Dedication waiver (http://creativecommons.org/publicdomain/zero/1.0/) applies to the data made available in this article, unless otherwise stated in a credit line to the data. 


\section{Background}

The concept of health literacy (HL) is closely linked to conventional literacy and requires knowledge, motivation and competence needed to access, understand, evaluate and use the necessary health information in order for individuals to make health decisions in their daily life, enhance and maintain their quality of life and to prevent disease [1].

Although the levels of HL tend to vary across countries, it is noteworthy that they are generally low. In a study conducted in eight European countries, it was stated that $47.6 \%$ of the participants had inadequate and problematic levels of HL. It was reported that the average HL scores differed significantly among the countries and the insufficient HL levels were between 1.8 and $26.9 \%$ among these countries. It was also revealed that the Netherlands had the highest HL scores, while Bulgaria had the lowest [2]. Inadequate and problematic HL levels in adults vary between 11.4 and $85.4 \%$ in different countries [3-9]. In a national study carried out among adults in Turkey, it was revealed that $64.6 \%$ of the participants had inadequate and problematic levels of HL [10]. In another study, it was found that $52.7 \%$ of the participants had inadequate and problematic levels of HL [11]. In these studies, different measurement tools related to $\mathrm{HL}$ were used. Therefore results may differ.

The fact that HL levels are very low worldwide poses a major health concern. Low levels of HL are associated with increased hospitalization rates, lower use of healthcare, problems regarding the proper intake of medications, difficulty in interpreting labels and health messages, poor general health and increased mortality rates [12]. Additionally, smoking and alcohol abuse [1315] and low physical activity [16] behaviors which adversely affect health, and high health costs [17], are also associated with low levels of HL.

HL is associated with several demographic factors such as old age, low educational levels, low socioeconomic status and ethnic minorities [10, 11, 16, 18]. Although many researchers have focused on community-based $\mathrm{HL}$, only a few have set out to investigate different ethnic groups. In studies conducted in various countries, it has been reported that HL levels differ among ethnic groups and that ethnic minorities, in particular, have lower HL levels [18-21]. However, the HL levels of ethnic groups in Turkey have not been studied.

Health perception (HP) refers to an individual's personal beliefs and statements regarding their health status. $\mathrm{HP}$ is a subjective term and a strong indicator that reflects the physical, mental and social well-being state of an individual [22]. HP affects the health-seeking behaviors and health responsibility of individuals [23]. HP is also associated with $\mathrm{HL}$, as it is known to increase as HL increases [24-26].
HL has been recognized as a challenging subject in Turkey and is one of the most important issues to be dealt with to any improvement in the health system and to improve quality [27]. Understanding the prevalence of $\mathrm{HL}$ is the first step to developing evidence-based interventions to protect and promote public health and healthcare services [28]. Despite the growing interest of researchers in HL in recent years, it is not exactly known whether HL varies according to ethnic differences in Turkey, the explanatory reasons for this and its relationship between HP. Therefore, it is essential to understand the levels of HL among ethnic groups and their relationship with HP in order to address potential health problems and ethnic inequities in health and to implement health promotion strategies.

This study is the first to compare the trilogy of HL, HP and ethnicity. The present study aimed to reveal the relationship between $\mathrm{HL}$ and $\mathrm{HP}$ as well as evaluate the HL levels and the factors affecting HL in different ethnic groups. In this way, it aimed to fill in the gap in the literature.

\section{Methods \\ Design}

This cross-sectional study was conducted in the central district of Artuklu in the province of Mardin, which is located in the Southeastern Anatolia Region of Turkey, between March and June 2019.

\section{Background information about the study area}

Mardin, which has a population of 838,778 people, is a metropolitan city located in Southeastern Turkey. The population of the central district of Artuklu is 178,154 people. Mardin and its surrounding areas host various ethnic and religious communities and elements. Mardin has a much more heterogeneous population in terms of culture and ethnicity compared to any other city in Turkey. Different ethnic groups, consisting mostly of Kurdish, Arab, Turkish and Assyrian people, live together peacefully in Mardin, where the official language is Turkish. The majority of the population in the province of Mardin is of Kurdish origin. The second largest ethnic group is of Arab origin, while the minority group is of Assyrian origin. The ethnic groups of Kurdish, Arab and Turkish origin are Muslims, while the ethnic group of Assyrian origin is Christians [29].

\section{The study population and sampling}

The study population consisted of adult individuals of different ethnic groups aged between 18 and 65 years who live in the central district of Artuklu in Mardin. Snowball and convenience sampling methods were used for the selection of the study sample. In view of the prediction that valid and reliable data could be obtained 
and as the population of those of Assyrian origin is small and not fully recognized, snowball and convenience sampling method were used to reach this population. After reaching 150 people of Assyrian origin aged between 18 and 65, the same number of people of Turkish, Kurdish and Arab origin living in the same environment were included in the study. By reaching an equal number of people from each ethnic group, the field study was completed with a total of 600 people.

The inclusion criteria for the study were as follows: being aged between 18 and 65, being literate in Turkish, volunteering to participate in the study and having communicative skills.

\section{Data collection tools}

Data was collected using a "Personal Information Form", the European Health Literacy Scale Turkish Adaptation (EHLS-TR) and the Health Perception Scale (HPS).

\section{Personal information form}

This form was created by the researchers and included questions related to demographic information such as ethnic origin (Kurdish, Arab, Turkish and Assyrian origin), age (18-29, 30-39, 40-49, 50-65), gender (female, male), occupation (housewife, laborer, retired, student, civil servant, tradesman), marital status (married, single), family type (nuclear, extended), educational status (primary school, high school, university or higher), socioeconomic status (fairly high, high, moderate, poor), information regarding any diseases requiring regular medication (yes, no), the source for accessing health information (healthcare professionals, TV/radio, printed press, internet, family members, friends), the type of health facility first applied to in case of a need (family healthcare center, state hospital, private hospital) and the status of smoking and drinking alcohol (yes, no).

\section{The European health literacy scale-Turkish adaptation (EHLS-TR)}

The scale was developed by the European Health Literacy Research Consortium [30] and the validity and reliability of the Turkish version was performed by Abacigil et al. [11] It is a self-report scale developed to evaluate the HL of individuals aged 15 years and above. The conceptual framework includes three dimensions related to health (health care, disease prevention and health promotion) and four information processing competencies (accessing, understanding, appraising and applying) related to health-related decision-making and practices. The conceptual framework of the 47 -item scale consists of a matrix with 12 sub-dimensions. Each item is evaluated on a 4-point Likert scale, with 1 point $=$ Very hard, 2 points $=$ Hard, 3 points $=$ Easy and 4 points $=$ Very easy . The response 'I don't know' is coded as 5 . The total score that can be obtained from the scale is between 47 and 188. For ease of calculation, the total score was standardized to take a value between 0 and 50 . The level of health literacy was evaluated in four categories according to the score obtained as (0-25): inadequate health literacy, (> 25-33): problematic health literacy, (>33-42): sufficient health literacy and ( $>42-50)$ : excellent health literacy. The scale reliability was examined using Cronbach's alpha coefficient and the construct validity was assessed by principal axis factoring procedure. It was stated that the HLS-TR was a valid and reliable measuring instrument with appropriate psychometric characteristics. A statistically significant and high correlation was found between HLS-TR and sub-dimension scores. The Cronbach's alpha values of the Turkish version of the scale were found to be 0.95 for total HL, 0.86 for health care, 0.87 for disease prevention and 0.91 for promoting health (11). In the present study, these values were found to be $0.95,0.81,0.87$ and 0.88 , respectively. The EHLS-TR scale was chosen for this study as it is more comprehensive and can be used for international comparisons.

\section{Health perception scale (HPS)}

This scale was developed by Diamond et al. [31] and its validity and reliability were carried out by Kadıoğlu and Yıldız [32]. There are 15 items and 4 dimensions (control of center, self-awareness, certainty and importance of health) in HPS. It is a five-point Likert type scale. Six items of the scale are positive and 9 items are negative expressions. A minimum of 15 points and a maximum of 75 points can be obtained from the scale. The validity of the scale was evaluated with factor analysis and content-scope validity and reliability were evaluated with item-total score correlation, internal consistency and continuity methods. Kendal W analysis was used for content validity, and Cronbach's alpha coefficient was used for internal consistency, and Pearson correlation analysis was used for item analysis and test-retest analysis. It was stated that the Turkish version of the scale is a valid and reliable scale. In the study conducted by Kadıoğlu and Yıldız, Cronbach's alpha values were found to be 0.90 for the control of center dimension, 0.91 for the self-awareness dimension, 0.91 for the certainty dimension and 0.82 for the importance of health dimension. In the present study, these values were found to be $0.80,0.62,0.75$ and 0.60 , respectively. In our study, the Cronbach Alpha value of two dimensions (self-awareness and importance of health) was found to be low. This may be due to our sample being different and our data not being distributed normally. The HLS scale was chosen for this study because it is a scale with proven Turkish validity and reliability in this field. 


\section{Data collection}

Data collection was initially started amongst the least known ethnic group, which was those of Assyrian origin. This group was in the minority and their place of residence was not clearly known. Various methods were used to get in touch with these individuals. Governmental institutions, local organizations, congregations, churches and tradesmen were contacted. Thus, Assyrian individuals who met the inclusion criteria were interviewed in their residences and workplaces. Other ethnic groups with the same characteristics living in the same neighborhood were interviewed with the same methods. The participants were informed about the purpose of the study and their consent was obtained. The individuals who accepted agreed to participate in the study and complied with met the inclusion criteria were asked to complete a questionnaire form. Data were collected using the Ppaper and Ppencil interview (PAPI). Those who had difficulty in completing the questionnaire were assisted by the researchers. The data were collected by face-to-face interviews. A total of 64 participants who met the inclusion criteria did not agree to participate in the study and 17 people whose questionnaires forms were not fully completed were excluded from the study. The response average completion time lasted was 20-25 min.

\section{Data analysis}

The study data were analyzed using SPSS 16.0 for Windows (SPSS Inc., Chicago, IL, USA). Descriptive statistics (averages and percentages), normality tests, MannWhitney U Test, Kruskal-Wallis Test, multiple regression and Spearman correlation were used in the analysis of the data. Bonferroni-corrected Mann-Whitney U test was used as a post-hoc procedure to determine the source of the difference as a result of the Kruskal-Wallis Test. The Cronbach's alpha coefficient was used in the analysis of the internal consistency of the scales. All the findings were tested at a significance level of 0.05 .

\section{Ethical approval}

This study was prepared in accordance with the guidelines of the Helsinki Declaration. The study was approved by Non-Interventional Ethics Committee (27.11.2018, 2018 / 1-1) of Mardin Artuklu University. Necessary legal permissions were obtained from the relevant institution. İnformed consent was obtained from all participants who volunteered to participate in the study.

\section{Results}

It was determined that among the participants, $36.8 \%$ of them included in the study were aged between 18 and 29 years. $58.8 \%$ of the participants were male and $63.2 \%$ of them were married. 54.3\% of the participants smoked, while $27.7 \%$ of them drank alcohol.

In the study, there was a statistically significant difference between the ethnic groups in terms of age, marital status, family type, educational status, economic status and occupation $(p<0.05)$ (Table 1$)$.

A statistically significant difference was found between ethnic origin and HL levels $(p=0.000)$. In the categorical evaluation (inadequate, problematic, sufficient, excellent health literacy), $80.7 \%$ of all of the participants included in the study had limited (inadequate and problematic) HL levels. While most of the participants of Kurdish origin $(85.3 \%)$ had inadequate HL levels, those of Assyrian origin had the most sufficient (46.7\%) levels (Table 2).

There was a statistically significant relationship between ethnic origin, age, family type, socioeconomic status, the source for accessing health information, smoking and drinking alcohol and HP levels $(p<0.05)$. The levels of HP of those of Assyrian origin, those aged between 50 and 65, those living in a nuclear family, those with high socioeconomic status, those who received health information mostly from healthcare professionals, those who consumed alcohol and non-smokers were higher than the other groups. There was a significant relationship between all the variables and HL levels except for the following variables: a disease requiring regular use of medication, gender and marital status. The data revealed that the participants with high HL were likely to be of Assyrian origin, be between the ages of $50-65$, be living in a nuclear family, be secondary school graduates, have a high socioeconomic status, be retired, evaluate their health status as good, obtain health information from healthcare professionals, apply to the state hospitals in emergencies, smoke and drink alcohol $(p<0.05)$, (Table 3).

A statistically significant correlation was determined between the HL and HP total scores of the participants. There was a moderately positive $(r=0.454 p=0.000)$ correlation between the HL and HP scores (Table 4).

\section{Discussion}

The results showed that those of Assyrian origin had the highest average HL score, while those of Kurdish origin had the lowest score. When the proportion of people with limited (inadequate and problematic) HL among the ethnic groups are considered (ranged from 51.3 to 99.3\%), it is obvious that the levels of HL pose an important public health problem for the region. Although these ethnic groups live in the same cultural environment, they have different characteristics in terms of religion, beliefs and various cultural aspects. As such, their access, understanding and use of health information may differ and this study has revealed ethnic group with 
Table 1 The relationship between ethnic origin and demographic variables

\begin{tabular}{|c|c|c|c|c|c|c|}
\hline Characteristics & $\begin{array}{l}\text { Turkish } \\
\text { origin } \\
\mathrm{n}(\%)\end{array}$ & $\begin{array}{l}\text { Kurdish origin } \\
\mathrm{n}(\%)\end{array}$ & Assyrian origin $\mathrm{n}(\%)$ & $\begin{array}{l}\text { Arab origin } \\
n(\%)\end{array}$ & $\begin{array}{l}\text { Total } \\
\text { n (\%) }\end{array}$ & $\begin{array}{l}x^{2} \\
p\end{array}$ \\
\hline \multicolumn{7}{|l|}{ Age } \\
\hline $18-29$ & $72(32.6)$ & $41(18.6)$ & $20(9.0)$ & $88(39.8)$ & $221(100.0)$ & 102.43 \\
\hline $30-39$ & $44(20.6)$ & $72(33.6)$ & $58(27.1)$ & $40(18.7)$ & $214(100.0)$ & 0.000 \\
\hline $40-49$ & $28(18.7)$ & $27(23.7)$ & $44(38.6)$ & $15(13.2)$ & $114(100.0)$ & \\
\hline $50-65$ & $6(11.8)$ & $10(19.6)$ & $28(54.9)$ & $7(13.7)$ & $51(100.0)$ & \\
\hline \multicolumn{7}{|l|}{ Gender } \\
\hline Female & $57(23.1)$ & $58(23.5)$ & $68(7.5)$ & $64(25.9)$ & $247(100.0)$ & 2.22 \\
\hline Male & $93(26.3)$ & $92(26.1)$ & $82(23.2)$ & $86(24.4)$ & $353(100.0)$ & .527 \\
\hline \multicolumn{7}{|l|}{ Marital status } \\
\hline Married & $84(22.2)$ & $99(26.1)$ & 112 (29.6) & $84(22.2)$ & $379(100.0)$ & 15.66 \\
\hline Single & $66(29.9)$ & $51(23.1)$ & $38(17.2)$ & $66(29.9)$ & $221(100.0)$ & 0.001 \\
\hline \multicolumn{7}{|l|}{ Family type } \\
\hline Nuclear & $48(23.5)$ & $37(18.1)$ & $94(46.1)$ & $25(12.3)$ & $204(100.0)$ & 81.105 \\
\hline Extended & $102(25.8)$ & $113(28.5)$ & $56(14.1)$ & 125 (31.6) & $396(100.0)$ & 0.000 \\
\hline \multicolumn{7}{|l|}{ Educational status } \\
\hline Primary school & $31(13.5)$ & $52(22.7)$ & $99(43.2)$ & $47(20.5)$ & $229(100.0)$ & \\
\hline High School & $80(32.0)$ & $62(24.8)$ & $35(14.0)$ & $73(29.2)$ & $250(100.0)$ & 73.90 \\
\hline University or higher & $39(32.2)$ & $36(29.8)$ & $16(13.2)$ & $30(24.8)$ & $121(100.0)$ & 0.000 \\
\hline \multicolumn{7}{|l|}{ Economic status } \\
\hline Fairly high & $22(47.8)$ & $21(45.7)$ & $3(6.5)$ & $0(0.0)$ & $46(100.0)$ & 82.062 \\
\hline High & $84(23.7)$ & $75(21.1)$ & 119 (33.5) & 77 (21.7) & $355(100.0)$ & 0.000 \\
\hline Moderate & $44(23.3)$ & $50(26.5)$ & $23(12.2)$ & $72(38.1)$ & $189(100.0)$ & \\
\hline Poor & $0(0.0)$ & $44(0.0)$ & $5(50.0)$ & $1(10.0)$ & $10(100.0)$ & \\
\hline \multicolumn{7}{|l|}{ Occupation } \\
\hline Housewife & $20(16.4)$ & $25(20.5)$ & $48(39.3)$ & $29(23.8)$ & $122(100.0)$ & \\
\hline Laborer & $26(22.4)$ & $35(30.2)$ & $12(10.3)$ & $43(37.1)$ & $116(100.0)$ & \\
\hline Retired & $3(20.0)$ & $3(20.0)$ & $4(26.7)$ & $5(33.3)$ & $15(100.0)$ & 139.714 \\
\hline Student & $37(45.1)$ & $7(8.5)$ & $4(4.9)$ & $34(41.5)$ & $82(100.0)$ & 0.000 \\
\hline Civil servant & $33(35.1)$ & $39(41.5)$ & $8(8.5)$ & $14(14.9)$ & $94(100.0)$ & \\
\hline Tradesman & $31(18.1)$ & $41(24.1)$ & $74(43.3)$ & 25 (14.6) & $171(100.0)$ & \\
\hline
\end{tabular}

Table $2 \mathrm{HL}$ levels of the ethnic groups

\begin{tabular}{|c|c|c|c|c|c|c|}
\hline Ethnic origin & $\begin{array}{l}\text { Inadequate } \\
\text { n (\%) }\end{array}$ & $\begin{array}{l}\text { Problematic } \\
\text { n (\%) }\end{array}$ & $\begin{array}{l}\text { Sufficient } \\
\text { n (\%) }\end{array}$ & $\begin{array}{l}\text { Excellent } \\
\text { n (\%) }\end{array}$ & $\begin{array}{l}\text { Total } \\
\text { n (\%) }\end{array}$ & $\begin{array}{l}x^{2} \\
p\end{array}$ \\
\hline Turkish origin & $54(36.0)$ & $92(61.3)$ & $4(2.7)$ & $0(0.0)$ & $150(100.0)$ & \\
\hline Kurdish origin & $128(85.3)$ & $21(14.0)$ & $1(0.7)$ & $0(0.0)$ & $150(100.0)$ & 324.09 \\
\hline Assyrian origin & $14(9.3)$ & $63(42.0)$ & $70(46.7)$ & $3(2.0)$ & $150(100.0)$ & 0.000 \\
\hline Arab origin & $20(13.4)$ & $92(61.3)$ & $38(25.3)$ & $0(0.0)$ & $150(100.0)$ & \\
\hline Total HL & $216(36.0)$ & $268(44.7)$ & $113(18,8)$ & $3(0.5)$ & $600(100.0)$ & \\
\hline
\end{tabular}


Table 3 Comparison of HP and HL scale scores in terms of sociodemographic characteristics

\begin{tabular}{|c|c|c|c|c|c|c|c|c|c|}
\hline \multirow[t]{2}{*}{ Ethnic origin } & \multicolumn{5}{|c|}{ HP scale scores } & \multicolumn{4}{|c|}{ HL scale scores } \\
\hline & $\bar{N}$ & $\overline{\mathrm{X}} \pm \mathrm{SS}$ & $x^{2 / z}$ & $p$ & Diff.*** & $\overline{\mathrm{X}} \pm \mathrm{SS}$ & $x^{2 / z}$ & $p$ & Diff. $* * *$ \\
\hline Turkish origin & 150 & $41.78 \pm 2.16$ & & & $a-b, a-c$ & $26.24 \pm 2.49$ & & & $a-b, a-c$, \\
\hline${ }^{b}$ Kurdish origin & 150 & $41.00 \pm 2.20$ & $117.013^{*}$ & 0.000 & $a-d, b-c$ & $23.04 \pm 2.17$ & $315.934^{*}$ & 0.000 & $a-d, b-c$, \\
\hline${ }^{\mathrm{C}}$ Assyrian origin & 150 & $45.28 \pm 4.74$ & & & $b-d, c-d$ & $32.36 \pm 5.49$ & & & $b-d, c-d$ \\
\hline${ }^{\mathrm{d}}$ Arab origin & 150 & $42.00 \pm 3.49$ & & & & $30.25 \pm 4.08$ & & & \\
\hline \multicolumn{10}{|l|}{ Age } \\
\hline${ }^{\mathrm{a}} 18-29$ & 221 & $42.50 \pm 3.38$ & & & & $28.23 \pm 4.97$ & & & \\
\hline$b_{30-39}$ & 214 & $42.45 \pm 3.64$ & $8.564^{*}$ & 0.036 & $a-d, b-c$ & $27.09 \pm 5.12$ & $14.249^{*}$ & 0.003 & $a-b, b-c$ \\
\hline$c^{c} 40-49$ & 114 & $43.50 \pm 4.31$ & & & $b-d$ & $28.26 \pm 5.06$ & & & $b-d$ \\
\hline$d_{50-65}$ & 51 & $43.58 \pm 3.24$ & & & & $29.89 \pm 6.40$ & & & \\
\hline \multicolumn{10}{|l|}{ Gender } \\
\hline Female & 247 & $42.73 \pm 3.77$ & $-.357^{* *}$ & 0.72 & & $28.22 \pm 5.26$ & $-.974 * *$ & 0.328 & \\
\hline Male & 353 & $42.79 \pm 3.61$ & & & & $27.80 \pm 5.19$ & & & \\
\hline \multicolumn{10}{|l|}{ Marital status } \\
\hline Married & 379 & $42.95 \pm 3.62$ & $-1.753^{* *}$ & 0.080 & & $28.05 \pm 5.38$ & $-.221^{* *}$ & 0.825 & \\
\hline Single & 221 & $42.44 \pm 3.76$ & & & & $27.83 \pm 4.95$ & & & \\
\hline \multicolumn{10}{|l|}{ Family type } \\
\hline Nuclear & 204 & $43.49 \pm 4.38$ & $-3.446^{* *}$ & 0.001 & & $29.57 \pm 5.97$ & $-4.669^{* *}$ & 0.000 & \\
\hline Extended & 396 & $42.39 \pm 3.20$ & & & & $27.15 \pm 4.59$ & & & \\
\hline \multicolumn{10}{|l|}{ Educational status } \\
\hline aPrimary school & 77 & $43.31 \pm 4.47$ & $3.569^{*}$ & 0.312 & & $28.74 \pm 5.22$ & $9.411^{*}$ & 0.024 & \\
\hline 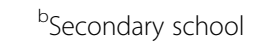 & 152 & $43.25 \pm 4.13$ & & & & $28.90 \pm 5.73$ & & & \\
\hline${ }^{\circ}$ High school & 250 & $42.31 \pm 2.81$ & & & & $27.38 \pm 4.68$ & & & $a-c, b-c$ \\
\hline${ }^{d}$ University or higher & 121 & $42.76 \pm 4.01$ & & & & $27.53 \pm 5.45$ & & & \\
\hline \multicolumn{10}{|l|}{ Economic status } \\
\hline${ }^{\mathrm{a}}$ Fairly high & 46 & $41.69 \pm 3.16$ & & & & $24.70 \pm 2.61$ & & & \\
\hline bHigh & 355 & $43.09 \pm 3.53$ & $14.893^{*}$ & 0.002 & $a-b, b-c$ & $28.77 \pm 5.32$ & $31.144^{*}$ & 0.000 & $a-b, a-c$, \\
\hline${ }^{c}$ Moderate & 189 & $42.41 \pm 4.01$ & & & & $27.23 \pm 4.92$ & & & $b-c$ \\
\hline${ }^{d}$ Poor & 10 & $42.70 \pm 3.30$ & & & & $28.69 \pm 8.51$ & & & \\
\hline \multicolumn{10}{|l|}{ Occupation } \\
\hline${ }^{a}$ Housewife & 122 & $42.98 \pm 4.01$ & & & & $28.89 \pm 5.39$ & & & \\
\hline bLaborer & 116 & $42.54 \pm 3.38$ & & & & $28.06 \pm 5.05$ & & & \\
\hline${ }^{c}$ Retired & 15 & $42.60 \pm 2.41$ & $8.436^{*}$ & 0.134 & & $29.74 \pm 6.15$ & $28.350^{*}$ & 0.000 & $a-e, b-e$, \\
\hline${ }^{\mathrm{d}}$ Student & 82 & $42.06 \pm 3.49$ & & & & $28.29 \pm 4.54$ & & & $c-e, d-e$, \\
\hline${ }^{\mathrm{e}}$ Civil servant & 94 & $42.22 \pm 2.77$ & & & & $25.55 \pm 3.98$ & & & $f-e$ \\
\hline${ }^{\mathrm{f}}$ Tradesman & 171 & $43.42 \pm 4.14$ & & & & $28.28 \pm 5.68$ & & & \\
\hline \multicolumn{10}{|l|}{ Evaluation of health status } \\
\hline${ }^{\mathrm{a}}$ Great & 28 & $42.14 \pm 6.93$ & & & & $26.10 \pm 5.72$ & & & \\
\hline${ }^{b}$ Good & 448 & $42.88 \pm 3.49$ & $7.136^{*}$ & 0.068 & & $28.42 \pm 4.95$ & $27.473^{*}$ & 0.000 & $a-b, b-c$ \\
\hline${ }^{c}$ Moderate & 114 & $42.57 \pm 3.30$ & & & & $26.73 \pm 5.50$ & & & \\
\hline${ }^{d}$ Poor & 10 & $41.50 \pm 3.02$ & & & & $27.40 \pm 8.94$ & & & \\
\hline \multicolumn{10}{|c|}{ Any disease requiring regular medication } \\
\hline Yes & 90 & $42.16 \pm 3.18$ & $-1.552^{* *}$ & 0.121 & & $27.51 \pm 5.55$ & $-1.48^{* *}$ & 0.251 & \\
\hline No & 510 & $42.87 \pm 3.75$ & & & & $28.05 \pm 5.16$ & & & \\
\hline
\end{tabular}


Table 3 Comparison of HP and HL scale scores in terms of sociodemographic characteristics (Continued)

\begin{tabular}{|c|c|c|c|c|c|c|c|c|c|}
\hline \multirow[t]{2}{*}{ Ethnic origin } & \multicolumn{5}{|c|}{ HP scale scores } & \multicolumn{4}{|c|}{ HL scale scores } \\
\hline & $\overline{\mathrm{N}}$ & $\overline{\mathrm{X}} \pm \mathrm{SS}$ & $x^{2 / z}$ & $p$ & Diff.*** & $\overline{\mathrm{X}} \pm \mathrm{SS}$ & $x^{2 / z}$ & $p$ & Diff. ${ }^{* * *}$ \\
\hline \multicolumn{10}{|c|}{ The source from which health information is obtained } \\
\hline aHealthcare professionals & 248 & $43.35 \pm 4.24$ & $21.126^{*}$ & & & $29.73 \pm 4.46$ & $99.12^{*}$ & & \\
\hline${ }^{\mathrm{b}}$ TV/Radio & 136 & $42.52 \pm 3.13$ & & & $a-d, b-d$ & $26.67 \pm 5.70$ & & & $a-d, b-d$ \\
\hline${ }^{C}$ Printed press & 43 & $41.90 \pm 2.57$ & & 0.001 & $c-d, e-d$ & $25.78 \pm 5.09$ & & 0.000 & $c-d, e-d$ \\
\hline${ }^{d}$ Internet & 97 & $43.32 \pm 3.39$ & & & $f-d$ & $28.58 \pm 5.23$ & & & $f-d$ \\
\hline${ }^{\mathrm{e}}$ Family members & 46 & $41.30 \pm 2.51$ & & & & $25.06 \pm 4.11$ & & & \\
\hline${ }^{\mathrm{f}}$ Friends & 32 & $41.18 \pm 3.49$ & & & & $25.02 \pm 4.80$ & & & \\
\hline \multicolumn{10}{|c|}{ The type of health facility first applied to in case of a need } \\
\hline${ }^{\mathrm{a}}$ Family healthcare center & 142 & $42.20 \pm 3.29$ & & & & $25.32 \pm 3.78$ & & & \\
\hline bState hospital & 406 & $42.77 \pm 3.43$ & $5.764^{*}$ & 0.056 & & $28.80 \pm 5.32$ & $49.073^{*}$ & 0.000 & $a-b, a-c$ \\
\hline${ }^{\mathrm{C}}$ Private hospital & 52 & $44.30 \pm 5.65$ & & & & $28.75 \pm 5.49$ & & & \\
\hline \multicolumn{10}{|l|}{ Smoking status } \\
\hline${ }^{\mathrm{a} S t i l l ~ s m o k i n g ~}$ & 326 & $43.09 \pm 3.51$ & & & & $28.94 \pm 5.43$ & & & \\
\hline${ }^{\mathrm{b}}$ Given up & 158 & $41.67 \pm 2.53$ & $20.456^{*}$ & 0.000 & $a-b, b-c$ & $26.57 \pm 4.09$ & $24.188^{*}$ & 0.000 & $a-b, a-c$ \\
\hline${ }^{\mathrm{c}}$ Never smoked & 116 & $43.35 \pm 4.96$ & & & & $27.12 \pm 5.46$ & & & \\
\hline \multicolumn{10}{|l|}{ Drinking alcohol } \\
\hline Yes & 166 & $44.56 \pm 4.67$ & $-7.275^{* *}$ & 0.000 & & $31.11 \pm 5.82$ & $-8.339^{* *}$ & 0.000 & \\
\hline No & 434 & $42.08 \pm 2.95$ & & & & $26.77 \pm 4.43$ & & & \\
\hline
\end{tabular}

* Kruskal Wallis Test

**Mann-Whitney U Test

*** Bonferroni-corrected Mann-Whitney $U$ test was used as post-hoc procedure to determine the source of the difference as a result of the Kruskal-Wallis Test

a-f Post-hoc analysis

Kurdish origin has the highest proportion of people with inadequate $\mathrm{HL}$.

To the researchers' knowledge, the present study is the first to provide a comparison of HL levels among individuals of different ethnic backgrounds living in Turkey. Therefore, the results of the present study regarding HL levels in different ethnic groups could not be compared with the findings of existing national studies. Compared to the other community-based studies conducted in Turkey $[10,11,33,34]$, it is noteworthy that the inadequate HL levels in the present study were significantly higher. Considering the connection between $\mathrm{HL}$ and fundamental literacy, this could be explained by the fact that the literacy levels are lower in southeastern Turkey compared to other regions [35]. The findings of the studies conducted among ethnic groups in many

Table 4 The correlations between the mean scores of the HL and the mean scores of the HP

\begin{tabular}{lll}
\hline Scales $^{\text {a }}$ & HL scale & HP scale \\
\hline HL scale & 1 & $r=0.454^{\mathrm{b}}$ \\
HP scale & & $p=0.000$ \\
& $r=0.454^{\mathrm{b}}$ & 1 \\
\hline
\end{tabular}

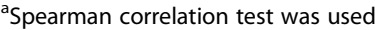

${ }^{b}$ The correlations are significant at 0.01 level countries have revealed different conclusions regarding the levels of HL. For example, in a study conducted with women of different ethnicities in Taiwan, one third of the women had an inadequate HL level and the HL levels of Taiwanese women were found to be higher than those of ethnic minorities [19]. In a study conducted with young adults in Amsterdam, the HL of $17.0 \%$ of the participants was found to be low and young Dutch adults were determined to have scored higher in terms of HL compared to other ethnic groups [20]. In a study conducted among refugees in Sweden, it was shown that three-fifths of the participants had inadequate and problematic HL [36]. In a study conducted in European countries, it was observed that approximately half of the individuals had inadequate and problematic HL [2]. Results in this study were also compared with studies using different HLS. This can make a difference in comparing results. The ethnic groups included in the present study differ from those in other countries as they have been living in this country together for a long time. Although those of Assyrian origin, especially those living in Mardin, are numerically less than other ethnic groups and differ from the other ethnic groups in terms of religion, beliefs and various cultural aspects, they have many common characteristics (eating and drinking, clothing, social life, etc.) with other cultures. Therefore, the HL 
levels of ethnic groups in Mardin may be affected differently.

The results of this study showed that the levels of HL were associated with several variables such as age, family type, educational status, economic status, occupation, and evaluation of one's health status. The data revealed that the participants with high HL were likely to be of Assyrian origin, be between the ages of 50-65, be living in a nuclear family, be secondary school graduates, have a high socioeconomic status, be retired, evaluate their health status as good, obtain health information from healthcare professionals, apply to the state hospitals in emergencies, smoke and drink alcohol. The results of many studies conducted among adult individuals in different countries have shown that those more likely to have low HL levels are older adults, unemployed people, individuals with low educational and low-income levels [37-39]. Furthermore, it has been revealed that those who evaluate their own health as bad also have a low level of HL $[5,36,40]$. These findings, indicating that some social groups have low levels of HL, seem to show that there are various social factors involved in HL. The findings in the literature are generally similar to those of the present study. However, contrary to the findings in the literature, the HL scores of the elderly (aged between 50 and 65 years) were higher in the present study. A similar result was also obtained in a study conducted in Japan [6]. Furthermore, another result that was different from those in the literature was that those with a low education level had higher HL. In this study, the fact that individuals of Assyrian origin had the highest HL scores and tended to be older might have contributed to the high HL scores of the elderly individuals. Individuals of Assyrian origin might have their specific ways to achieve and use information on health more, which might also contribute to higher HL scores.

It should be noted that the HL scores among smokers and drinkers of alcohol were surprisingly higher than non-smokers and non-drinkers. Contrary to this finding, several studies in the literature have indicated a negative relationship between HL and smoking [13, 14, 41]. Garcia-Codina et al. [40] reported that those who drank less alcohol had sufficient HL levels compared to heavy drinkers and non-drinkers. Furthermore, Amoah et al. [15] found that poor functional HL was associated with alcohol abuse. There are limited studies revealing the relationship between HL and smoking and alcohol abuse. In order to verify this relationship and explain this unexpected result of the present study, it is significantly important to conduct more extensive research that also reveals to explore the causal relationships between smoking and drinking alcohol abuse and HL.

It is important for all individuals to possess the skills that enable them to access and select reliable sources of information. The efforts to seek information with these skills are central to the processes by which HL affects health outcomes. In a study conducted in the USA, it was stated that the participants mostly considered health professionals as a reliable source of health information [42]. In other studies, it has also been shown that health professionals are the most preferred source of information [43-45]. Health professionals are always among the top three sources sought for health information and the first reliable source of health information in Turkey [46]. These findings are consistent with the results of the present study.

Another important result of this study was that as HL levels increased, the HP levels of individuals increased. $\mathrm{HP}$ is associated with individuals' health protection and development behaviors, self-care management, and levels of HL in general [47]. Although the studies investigating the relationship between HL and HP are limited, some studies have reported results supporting the positive relationship between HL and HP [24, 26, 47-50]. In this context, it can be suggested that individuals with sufficient levels of HL are more likely to seek health information, protect and promote their health, and look for solutions in cases of illness.

This study is the first step to conducting future studies in Turkey measuring the levels of HL among ethnic groups with larger sample size. In the light of these data, programs to increase HL should be developed in Mardin, especially for disadvantaged groups. In order to increase the HL level of the public to the desired level, it is important to include HL lessons in the curriculums at schools. Also, in-service trainings must be organized for healthcare employees to develop programs to increase the HL levels of the society. These interventions will likely help improve the health literacy of individuals. However, more quantitative and qualitative research is required to investigate HL levels and the factors affecting the levels of the ethnic groups living in Mardin and to identify strategies to tackle the challenges.

\section{Research limitations}

The limitations of this study are as follows: 1) As the study was carried out in only a certain geographical region, the results cannot be generalized to the whole of the Turkish population, 2) As the improbable sampling method was used, there are certain limitations in generalizing the findings in the study group, 3) The answers given to the questions may include recall bias as the study was conducted as a cross-sectional design. 4) The total scores of the scales were evaluated while the subscales were not compared, which can lead to poorer predictions of HL and HP levels. 5) Only people who understood Turkish were included in the study and disadvantaged groups who did not speak Turkish were not 
included. Future studies may consider exploring the HL of these ethnic groups. However, the fact that there are no studies in the literature evaluating ethnic groups in terms of HL and HP is the strength of the present study.

\section{Conclusion}

The findings showed that inadequate levels of HL were dramatically high among the ethnic groups in general and that those of Kurdish origin were the most disadvantaged group. It was considered striking that older people, those with low educational levels and those who smoke and drank alcohol had higher HL scores. In addition, a moderately positive relationship was determined between HL and HP. This study provided insights into the HL status of ethnic groups in Turkey. Further studies are required to identify strategies to help improve the HL of these ethnic groups.

\section{Abbreviations}

EHLS-TR: The European Health Literacy Scale-Turkish Adaptation; HL: Health Literacy; HP: Health perception; HPS: Health Perception Scale; SPSS: Statistical Package for Social Sciences; USA: United States of America

\section{Acknowledgments}

We would like to thank all participants who volunteered for this study.

\section{Authors' contributions}

GY and VBD: Conceived and designed the study. GY: Created the first draft of the manuscript. VBD and SÇ: Assisted with data collection and edited the manuscript. SÇ: Performed data analysis and edited the manuscript. GY: Edited the manuscript. All authors approved the final version of the manuscript.

\section{Funding}

No financial support was received for this study.

\section{Availability of data and materials}

The datasets used and/or analyzed during the current study are available from the corresponding author on reasonable request.

\section{Declarations}

\section{Ethics approval and consent to participate}

This study was prepared in accordance with the guidelines of the Helsinki Declaration. The study was approved by Non-Interventional Ethics Committee $(27.11 .2018,2018$ / 1-1) of Mardin Artuklu University. Necessary legal permissions were obtained from the relevant institution. Informed consent was obtained from all participants who volunteered to participate in the study.

\section{Consent for publication}

Not applicable.

\section{Competing interests}

The authors declare that they have no competing interests.

\section{Author details}

'Department of Nursing, Diyarbakir Atatürk School of Health, Dicle University, Diyarbakır, Turkey. ${ }^{2}$ Department of Nursing, Faculty of Health Sciences, Mardin Artuklu University, Mardin, Turkey.

Received: 30 December 2020 Accepted: 21 May 2021

Published online: 10 June 2021

\section{References}

1. Sørensen K, Van den Broucke S, Fullam J, Doyle G, Pelikan J, Slonska Z, et al. Health literacy and public health: a systematic review and integration of definitions and models. BMC Public Health. 2012;12(1):80. https://doi.org/1 0.1186/1471-2458-12-80.

2. Sørensen K, Pelikan JM, Röthlin F, Ganahl K, Slonska Z, Doyle G, et al. Health literacy in Europe: comparative results of the European health literacy survey (HLS-EU). Eur J Pub Health. 2015;25(6):1053-8. https://doi.org/10.1 093/eurpub/ckv043.

3. Kutner M, Greenburg E, Jin Y, Paulsen C. The Health Literacy of America's Adults: Results from the 2003 National Assessment of Adult Literacy: National Center for Education Statistics; 2006. http://ies.ed.gov/pubsearch/ pubsinfo.asp?pubid=2006483 [Accessed 30 Apr 2020]

4. Von Wagner C, Knight K, Steptoe A, Wardle J. Functional health literacy and health-promoting behaviour in a national sample of British adults. J Epidemiol Community Health. 2007;61(12):1086-90. https://doi.org/10.1136/ jech.2006.053967.

5. Ehmann AT, Groene O, Rieger MA, Siegel A. The relationship between health literacy, quality of life, and subjective health: results of a crosssectional study in a rural region in Germany. Int J Environ Res Public Health. 2020;17(5):1683. https://doi.org/10.3390/ijerph17051683.

6. Nakayama K, Osaka W, Togari T, Ishikawa H, Yonekura Y, Sekido A, et al. Comprehensive health literacy in Japan is lower than in Europe: a validated Japanese-language assessment of health literacy. BMC Public Health. 2015; 15(1):505. https://doi.org/10.1186/s12889-015-1835-x.

7. Tavousi M, Mehrizi A, Solimanian A, Sarbandi F, Ardestani M, Hashemi A, et al. Health literacy in Iran: findings from a national study. Payesh. 2016;15: 95-102 http://payeshjournal.ir/article-1-199-en.html [Accessed 29 April 2020].

8. Levin-Zamir D, Baron-Epel OB, Cohen V, Elhayany A. The association of health literacy with health behavior, socioeconomic indicators, and selfassessed health from a national adult survey in Israel. J Health Commun. 2016;21(sup2):61-8. https://doi.org/10.1080/10810730.2016.1207115.

9. Lee SYD, Tsai TI, Tsai YW, Kuo KN. Health literacy, health status, and healthcare utilization of Taiwanese adults: results from a national survey. BMC Public Health. 2010;10(1):614. https://doi.org/10.1186/1471-2458-10614.

10. Durusu-Tanrıöver M, Yildirim HH, Demiray Ready FN, Cakır B, Akalın HE. Turkey Health Literacy Survey. 1st ed. Ankara: Health-Sen Publications; 2014 http://www.sagliksen.org.tr/cdn/uploads/gallery/pdf/8dcec50aa18c21cda f86a2b33001a409.pdf. [Accessed 25 Apr 2020]

11. Abacigil F, Harlak H, Okyay P, Kiraz DE Gursoy Turan S, Saruhan G, et al: Validity and reliability of the Turkish version of the European health literacy survey questionnaire. Health Promot Int 2019;34:658-667. https://doi.org/1 0.1093/heapro/day020, 4

12. Berkman ND, Sheridan SL, Donahue KE, Halpern DJ, Crotty K. Low health literacy and health outcomes: an updated systematic review. Ann Intern Med. 2011;155(2):97-107. https://doi.org/10.7326/0003-4819-155-2-2011071 90-00005.

13. Hoover DS, Vidrine Jl, Shete S, Spears CA, Cano MA, Correa-Fernández V, et al. Health literacy, smoking, and health indicators in African American adults. J Health Commun. 2015;20(sup2):24-33. https://doi.org/10.1080/1081 0730.2015.1066465.

14. Fawns-Ritchie C, Starr JM, Deary IJ. Health literacy, cognitive ability and smoking: a cross-sectional analysis of the English longitudinal study of ageing. BMJ Open. 2018;8(10):e023929. https://doi.org/10.1136/bmjopen-201 8-023929.

15. Amoah PA, Koduah AO, Gyasi RM, Gwenzi GD, Anaduaka US. The relationship between functional health literacy, health-related behaviours, and sociodemographic characteristics of street-involved youth in Ghana. Int J Health Promot Educ. 2019;57(3):116-32. https://doi.org/10.1080/14635240.2 018.1552835.

16. Duplaga M. Determinants and consequences of limited health literacy in polish society. Int J Environ Res Public Health. 2020;17(2):642. https://doi. org/10.3390/ijerph17020642.

17. Howard DH, Gazmararian J, Parker RM. The impact of low health literacy on the medical costs of Medicare managed care enrollees. Am J Med. 2005; 118(4):371-7. https://doi.org/10.1016/j.amjmed.2005.01.010.

18. Bo A, Friis K, Osborne RH, Maindal HT. National indicators of health literacy: ability to understand health information and to engage actively with healthcare providers-a population-based survey among Danish adults. BMC Public Health. 2014;14(1):1095. https://doi.org/10.1186/1471-2458-14-1095.

19. Tsai HM, Cheng CY, Chang SC, Yang YM, Wang HH. Health literacy and health-promoting behaviors among multiethnic groups of women in 
Taiwan. J Obstet Gynecol Neonatal Nurs. 2014;43(1):117-29. https://doi.org/1 $0.1111 / 1552-6909.12269$.

20. Blom IM, Cohen ES, Eshuis LV, Woudstra AJ, Snijder MB, Kunst AE, et al. Ethnic differences in health literacy among young adults in Amsterdam. Health Lit Res Pract. 2018;2(4):e192-204. https://doi.org/10.3928/24748307-2 0180926-01.

21. Shaw SJ, Armin J, Torres CH, Orzech KM, Vivian J. Chronic disease selfmanagement and health literacy in four ethnic groups. J Health Commun. 2012;17(sup3):67-81. https://doi.org/10.1080/10810730.2012.712623.

22. Souto TS, Ramires A, Leite Â, Santos V, Santo RE. Health perception: validation of a scale for the portuguese population. Temas em Psicologia. 2018;26(4):2167-83. https://doi.org/10.9788/TP2018.4-17Pt.

23. Kaleta D, Polanska K, Dziankowska-Zaborszczyk E, Hanke W, Drygas W. Factors influencing self-perception of health status. Cent Eur J Public Health. 2009;17(3):122-7. https://cejph.szu.cz/pdfs/cjp/2009/03/02.pdf [Accessed 2 May 2020]. https://doi.org/10.21101/cejph.b0017.

24. Deniz SŞ, Özer Ö, Sonğur C. Effect of health literacy on health perception: an application in individuals at age 65 and older. Soc Work Public Health. 2018;33(2):85-95. https://doi.org/10.1080/19371918.2017.1409680.

25. van der Heide I, Wang J, Droomers M, Spreeuwenberg P, Rademakers J, Uiters E. The relationship between health, education, and health literacy: results from the Dutch adult literacy and life skills survey. J Health Commun. 2013;18(sup1):172-84. https://doi.org/10.1080/10810730.2013.825668.

26. Kim SH, Lee $\mathrm{E}$. The influence of functional literacy on perceived health status in Korean older adults. J Korean Acad Nurs. 2008;38(2):195-203. https://doi.org/10.4040/jkan.2008.38.2.195.

27. Özkan, S.: Turkey behavioral health workers health lıteracy development program. 2018. Ministry of Health Publications. ISBN No: 978-975-590-663-8 https://sbu.saglik.gov.tr/Ekutuphane/kitaplar/SOYA\%20S\%C4\%BONCAN\%2 ORAPORU.pdf [Accessed 2 May 2020].

28. Loer AKM, Domanska OM, Kuhnert R, Houben R, Albrecht S, Jordan S. Online survey for the assessment of generic health literacy among adolescents in Germany (GeKoJu): study protocol. Int J Environ Res Public Health. 2020;17(5):1518. https://doi.org/10.3390/ijerph17051518.

29. Arrk-Yüksel T. Roots tourısm: a research on Syriacs of Mardin. In: Unpublished master's thesis. Batman: Batman University; 2018.

30. HLS EU C: Comparative Report on Health Literacy in Eight EU Member States The European Health Literacy Survey, 2012. http://www.health-litera cy.eu (last accessed date 21 Apr 2016) [Accessed 6 May 2020].

31. Diamond JJ, Becker JA, Arenson CA, Chambers CV, Rosenthal MP. Development of a scale to measure adults' perceptions of health: priliminary findings. J Commun Psychol. 2007;35(5):557-61. https://doi.org/1 0.1002/jcop.20164.

32. Kadıoğlu H. Yıldız a:validity and reliability of Turkish version of perception of health scale. Turkiye Klinikleri J Med Sci. 2012;32(1):47-53. https://doi.org/10. 5336/medsci.2010-21761.

33. Örsal Ö, Duru P, Örsal Ö, Tirpan K, Çulhacı A. Analysis of the relationship among health awareness and health literacy, patient satisfaction levels with primary care in patients admitting to primary care health centers. Patient Educ Couns. 2019;102(2):376-82. https://doi.org/10.1016/..pec.2018.09.006.

34. Özdemir H, Alper Z, Uncu Y, Bilgel N. Health literacy among adults: a study from Turkey. Health Educ Res. 2010;25(3):464-77. https://doi.org/10.1093/ her/cyp068.

35. Turkey demographic and health survey: Hacettepe University Institute of Population Studies 2013. NEE-HU Publications. Ankara. ISBN 978-975-491390-3. http://www.hips.hacettepe.edu.tr/tnsa2013/rapor/TNSA_2013_ana_ra por.pdf [Accessed 2 May 2020].

36. Wångdahl J, Lytsy P, Mårtensson L, Westerling R. Health literacy among refugees in Sweden-a cross-sectional study. BMC Public Health. 2014;14(1): 1030. https://doi.org/10.1186/1471-2458-14-1030.

37. Berens EM, Vogt D, Messer M, Hurrelmann K, Schaeffer D. Health literacy among different age groups in Germany: results of a cross-sectional survey. BMC Public Health. 2016;16(1):1151. https://doi.org/10.1186/s12889-016-381 $0-6$.

38. Bernstein K, Han S, Park CG, Lee YM, Hong O. Evaluation of health literacy and depression literacy among Korean Americans. Health Educ Behav. 2020; 47(3):457-67. https://doi.org/10.1177/1090198120907887.

39. Toçi E, Burazeri G, Myftiu S, Sørensen K, Brand H. Health literacy in a population-based sample of adult men and women in a South Eastern European country. J Public Health. 2016;38:6-13. https://doi.org/10.1093/ pubmed/fdv006.
40. Garcia-Codina O, Juvinyà-Canal D, Amil-Bujan P, Bertran-Noguer C, González-Mestre MA, Masachs-Fatjo E, et al. Determinants of health literacy in the general population: results of the Catalan health survey. BMC Public Health. 2019;19(1):1122. https://doi.org/10.1186/s12889-019-7381-1.

41. Fernandez DM, Larson JL, Zikmund-Fisher BJ. Associations between health literacy and preventive health behaviors among older adults: findings from the health and retirement study. BMC Public Health. 2016;16(1):596. https:// doi.org/10.1186/s12889-016-3267-7.

42. Chen X, Hay JL, Waters EA, Kiviniemi MT, Biddle C, Schofield E, et al. Health literacy and use and trust in health information. J Health Commun. 2018; 23(8):724-34. https://doi.org/10.1080/10810730.2018.1511658.

43. Oedekoven M, Herrmann WJ, Ernsting C, Schnitzer S, Kanzler M, Kuhlmey A, et al. Patients' health literacy in relation to the preference for a general practitioner as the source of health information. BMC Fam Pract. 2019;20(1): 94. https://doi.org/10.1186/s12875-019-0975-y.

44. Tang C, Wu X, Chen X, Pan B, Yang X. Examining income-related inequality in health literacy and health-information seeking among urban population in China. BMC Public Health. 2019;19(1):221. https://doi.org/10.1186/s12889019-6538-2.

45. Abdel-Latif MM, Saad SY. Health literacy among Saudi population: a crosssectional study. Health Promot Int. 2019;34(1):60-70. https://doi.org/10.1093/ heapro/dax043.

46. Abacıgil F, Harlak H, Okyay P. In: Okyay P, Abacıgil F, editors. Turkish adaptation of the European health literacy scale (ASOY-TR): Ministry of Health Publications; 2016. https://sbu.saglik.gov.tr/Ekutuphane/kitaplar/ Sa\%C4\%9Fl\%C4\%B1 k\%200kur\%20Yazarl\%C4\%B1\%C4\%9F\%C4\%B1.pdf [Accessed 2 May 2020].

47. Durmaz $\mathrm{S}$, Sürücü $\mathrm{E}$, Ozvurmaz S. Determınatıon of health lıteracy, health perception levels and related factors of marble factory workers. Med Sci. 2020;15:81-91. https://doi.org/10.12739/NWSA.2020.15.3.1B0092.

48. Filiz E. The relationship between health literacy pregnancy and perception of health. In: Unpublished doctoral dissertation. Konya: Selçuk University; 2015.

49. Cho YI, Lee SYD, Arozullah AM, Crittenden KS. Effects of health literacy on health status and health service utilization amongst the elderly. Soc Sci Med. 2008;66(8):1809-16. https://doi.org/10.1016/j.socscimed.2008.01.003.

50. Akça E, Gökyıldız Sürücü \$̧, Akbaş M. Health perception, health literacy and related factors in pregnant women. J Inonu Univ Health Serv Vocation School. 2020;8:630-42. https://doi.org/10.33715/inonusaglik.735467.

\section{Publisher's Note}

Springer Nature remains neutral with regard to jurisdictional claims in published maps and institutional affiliations.

Ready to submit your research? Choose BMC and benefit from:

- fast, convenient online submission

- thorough peer review by experienced researchers in your field

- rapid publication on acceptance

- support for research data, including large and complex data types

- gold Open Access which fosters wider collaboration and increased citations

- maximum visibility for your research: over $100 \mathrm{M}$ website views per year

At BMC, research is always in progress.

Learn more biomedcentral.com/submissions 